\title{
Perinatal Hypophosphatasia: Tissue Levels of Vitamin B6 Are Unremarkable Despite Markedly Increased Circulating Concentrations of Pyridoxal-5'-Phosphate Evidence for an Ectoenzyme Role for Tissue-nonspecific Alkaline Phosphatase
}

\author{
Michael P. Whyte, "\# J. Dennis Mahuren, ${ }^{8}$ Kenton N. Fedde, ${ }^{\ddagger}$ F. Sessions Cole," Edward R. B. McCabe," and Stephen P. Coburn" \\ ${ }^{*}$ Metabolic Research Unit, Shriners Hospital for Crippled Children, St. Louis, Missouri 63131; ${ }^{\ddagger}$ Division of Bone and Mineral \\ Metabolism, Departments of Medicine and Pediatrics, Washington University School of Medicine, St. Louis, Missouri 63110; \\ ${ }^{\S}$ Department of Biochemistry, Fort Wayne State Developmental Center, Fort Wayne, Indiana 46835; "Department of Pediatrics, \\ Brigham and Women's Hospital, Harvard University School of Medicine, Boston, Massachusetts 02115; and 'Departments of \\ Pediatrics and Biochemistry, Biophysics, and Genetics, University of Colorado School of Medicine, Denver, Colorado 80262
}

\begin{abstract}
"Perinatal" hypophosphatasia is the most severe form of this inborn error of metabolism, which is characterized by deficient activity of the tissue-nonspecific (liver/bone/kidney) isoenzyme of alkaline phosphatase (ALP) (TNSALP). We report that autopsy tissue from three affected subjects, which was profoundly low in ALP activity, had essentially unremarkable levels of pyridoxal-5'-phosphate (PLP), pyridoxal, and total vitamin B6 content despite markedly elevated plasma PLP levels (5,800, 14,500, and 98,500 nM; adult norm, 5-109 nM).

Our findings help to explain the general absence of symptoms of vitamin B6 excess or deficiency in hypophosphatasia, and provide evidence that TNSALP acts as an ectoenzyme to regulate extracellular rather than intracellular concentrations of PLP (the cofactor form of vitamin B6) and perhaps other phosphate compounds.
\end{abstract}

\section{Introduction}

Alkaline phosphatase (ALP) ${ }^{1}$ (orthophosphoric-monoester phosphohydrolase [alkaline optimum] EC 3.1.3.1) is a ubiquitous plasma membrane-bound enzyme whose physiologic function is poorly understood despite considerable interest and investigation (1). A variety of studies, however, indicate an important role for the tissue-nonspecific (liver/bone/kidney) isoenzyme of ALP (TNSALP) in skeletal mineralization. For example, serum levels of bone ALP activity have been reported to reflect the rate of skeletal formation in vivo (2), and

This paper was presented in part at the Annual Meeting of the American Society of Human Genetics, November 2-5, 1986, Philadelphia, PA, and has appeared in abstract form (1986. Am. J. Hum. Genet. 39:A-87).

Address reprint requests to Dr. Whyte, Shriners Hospital for Crippled Children, 2001 S. Lindbergh Blvd., St. Louis, MO 63131.

Received for publication 15 April 1987 and in revised form 4 November 1987.

1. Abbreviations used in this paper: ALP, alkaline phosphatase; B6, vitamin B6; 4-PA, 4-pyridoxic acid; PL, pyridoxal; PLP, pyridoxal-5'phosphate; PM, pyridoxamine; PMP, pyridoxamine-5'-phosphate; PN, pyridoxine; TNSALP, tissue-nonspecific (liver/bone/kidney) ALP isoenzyme.

J. Clin. Invest.

(C) The American Society for Clinical Investigation, Inc.

$0021-9738 / 88 / 04 / 1234 / 06 \$ 2.00$

Volume 81, April 1988, 1234-1239 stereospecific inhibition of this enzyme with a variety of compounds will block calcification in vitro (3). Perhaps the best evidence for this physiologic function, however, came with discovery of hypophosphatasia by J. C. Rathbun in 1948 (4). Hypophosphatasia is an inborn error of metabolism (McKusick 14630, 24150, and 24151) characterized biochemically by deficient activity of TNSALP, wherein rickets/osteomalacia occur although circulating levels of calcium and inorganic phosphate are not subnormal (5). Defective skeletal mineralization in hypophosphatasia may be the result of endogenous accumulation of inorganic pyrophosphate, a natural substrate for TNSALP which can inhibit hydroxyapatite crystal formation, although other mechanisms are possible $(1,5,6)$.

Recently, we identified markedly increased plasma levels of pyridoxal-5'-phosphate (PLP), a cofactor form of vitamin B6 (B6), in all of 14 patients who represented nearly the complete clinical spectrum of hypophosphatasia (7). This finding indicated that TNSALP acts in B6 metabolism, and that PLP is also one of its natural substrates. Of interest, except for the occasional occurrence of seizures or nephrocalcinosis in the severe forms, we noted that manifestations of B6 deficiency or intoxication are generally absent in hypophosphatasia (7). This clinical observation appeared to be explained by our additional finding that circulating levels of pyridoxal (PL), the vitameric form of B6 which traverses plasma membranes (8), were normal or somewhat increased (7). Since PL is formed by dephosphorylation of PLP, TNSALP appeared to affect extracellular levels of PLP (7). These observations supported the hypothesis that TNSALP functions physiologically as an ectoenzyme. However, many investigators have concluded from a variety of in vitro evidence that ALP regulates intracellular levels of PLP and other phosphate compounds (9-11). Indeed, after our report of elevated plasma PLP levels in hypophosphatasia (7), additional studies of the intracellular B6 status of patients with hypophosphatasia were called for (12).

Herein, we report that in three subjects with the severe perinatal (lethal) form of hypophosphatasia and markedly elevated plasma PLP levels, tissues obtained at autopsy that were profoundly deficient in TNSALP activity had essentially unremarkable levels of PLP and other B6 vitamers. Our findings indicate that TNSALP acts as an ectoenzyme.

\section{Methods}

\section{Subjects}

Patient I. Patient I was a 31-wk (estimated gestational age), 1,700 g stillborn boy delivered to a 20 -yr-old Caucasian primagravida after prostaglandin induction of labor. She had been taking prenatal vita- 
mins. Ultrasound examination late in pregnancy to determine fetal age had revealed oligohydramnios, several anatomical defects, and marked skeletal hypomineralization. At delivery, radiographic studies were consistent with perinatal hypophosphatasia. Serum obtained from umbilical cord blood had only 6 IU/liter of ALP activity (135 and 109 IU/liter from two control newborns of 38 wk gestation). Autopsy studies revealed multiple congenital anomalies-including cleft lip and palate, hypoplastic lungs, cardiac defects, agenesis of one kidney, absent diaphragm, intraabdominal testes, fetal teeth, and polymicrogyria, as well as marked skeletal hypomineralization. Chromosomal studies, however, were unremarkable.

Patient II. Patient II was a 1,350-g boy of 32 wk gestation born to a 29-yr-old Caucasian primagravida. At birth, short limbs and wide fontanels were noted and he was cyanotic, limp, and apneic. He lived for $13 \mathrm{~d}$, during which time he was respirator dependent and was parenterally alimented with a solution that contained $0.6 \mathrm{mg}$ of pyridoxine (PN) hydrochloride daily. He also received nine transfusions of packed erythrocytes and phototherapy for hyperbilirubinemia. His hospital course was complicated by intracranial hemorrhage, thrombocytopenia, and group B streptococcal septicemia.

Patient III. Patient III was a 3,260-g girl of 41 wk gestation. She was noted to have a soft skull at birth. Radiographic studies suggested hypophosphatasia and serum ALP activity was < 5 IU/liter; she was hypotonic and fed poorly. Seizures (see below) with episodes of apnea began at $6 \mathrm{~d}$ of age, but did not respond to phenobarbital, valproate, diazepam, clonazepam, or a single intravenous dose of $10 \mathrm{mg} \mathrm{PN}$. $2 \mathrm{~d}$ later, she required mechanical ventilation because of respiratory distress from increased chest wall compliance. Subsequently, she received intravenous infusions of fresh-frozen pooled plasma thrice weekly for 5 mo, in the hope that we would observe the correction of hypophosphatasemia and clinical and radiographic improvement that we had noted previously in another patient treated in this way (13). There was no significant correction of her hypophosphatasemia, but instead, clinical and radiographic deterioration occurred. Myoclonus and seizures, temporally associated with recurrent episodes of profound bradycardia, continued. Since we were not certain of her tissue levels of B6, she received $50 \mathrm{mg} \mathrm{PN}$ i.v. once daily in an attempt to treat her epilepsy. At first, rapid improvement of her seizures occurred with PN, but this control deteriorated after 1-2 wk. At the time of her death, at age $6 \mathrm{mo}$, she was receiving $35 \mathrm{mg}$ PN orally each day. Unfortunately, only brain was available for biochemical study. Plasma was obtained for assay of B6 vitamers just before PN therapy, and while the patient received increasing doses of PN intravenously (Table I).

Controls. Control tissue samples were obtained at the autopsy of a full-term newborn, a 2-d-old infant, and a stillborn believed to be 26 wk gestational age (controls I-III, respectively). Each had died from cardiopulmonary disease. Umbilical cord blood was obtained from two different control subjects ( $A$ and $B$ ) for assay of serum ALP activity and plasma $\mathrm{B} 6$ vitamer levels.

\section{Tissue preparation}

Specimens from the patients and controls were collected within 12-24 $\mathrm{h}$ of death. Corpses had been kept in refrigerated vaults until autopsy. Frozen specimens from patients I and II and the control subjects I to III were processed simultaneously. Representative pieces of the tissues were weighed and then homogenized in distilled water.

Biochemical assays. ALP activity, protein, DNA, and B6 vitamer content were each measured in duplicate in the same aliquots of the original tissue homogenates. ALP activity was assayed by a kinetic method (14) using p-nitrophenylphosphate substrate in 2-amino, 2methyl-1-propanol buffer ( $\mathrm{pH} 10.5$ ) with a ultraviolet-spectrophotometer (Du-6; Beckman Instruments, Inc., Irvine, CA). Protein was quantitated spectrophotometrically using bovine serum protein as the standard (American Monitor Corp., Indianapolis, IN; Lot 29217-05). DNA was assayed by the method of LaBarca and Paigen (15). The seven major vitameric forms of B6 were assayed in tissue homogenate, serum, and plasma by the cation-exchange HPLC method of Coburn et al. (16).

\section{Results}

Table I summarizes the circulating levels of the vitameric forms of B6 in the three patients and in two control newborns, $A$ and $B$. Each of the patients had greatly elevated plasma PLP levels before death. Indeed, the plasma PLP concentrations of these patients with perinatal hypophosphatasia were, even before PN therapy, about twice what we had observed in two nonlethal cases of the infantile form of hypophosphatasia (7). Umbilical cord blood from stillborn patient I contained PLP levels that were 25 -fold greater than the average value for the two control newborns, and 53-fold greater than the upper limit of normal for 38 adult subjects (16). Patient II, who had been receiving $0.6 \mathrm{mg}$ of $\mathrm{PN}$ i.v. daily as part of his total parenteral nutrition, had even higher plasma PLP levels. Patient III had circulating PLP levels before PN therapy that were similar to patients I and II. However, during high dose PN therapy, in an attempt to control her seizures (see below), plasma PLP levels reached $\sim 1,000$-fold greater than the upper limit of normal for control adults.

Despite the massive elevation in patient plasma PLP concentrations, their circulating PL levels appeared to be increased only when they had received pharmacologic doses of PN (patients II and III). Indeed, plasma PL levels were not detected (sensitivity $>10 \mathrm{nM}$ ) before PN treatment. Nevertheless, circulating levels of the B6 degradation product, 4-pyridoxic acid (4-PA), were essentially unremarkable in each patient. PNP was not detected in blood from either patients or controls.

Table II summarizes the ALP activity in tissues, which was, as expected (5), markedly deficient in all patient samples except the small intestine. Patient jejunum had substantially more ALP activity compared with controls. Inhibition studies using L-phenyalanine (1) showed that this was, in fact, intestinal ALP isoenzyme (data not shown). Substantial amounts of ALP activity (but less than control) were found in what was believed at autopsy to be the one kidney from patient I.

Table I. Circulating Levels of B6 Vitamers in Perinatal Hypophosphatasia

\begin{tabular}{|c|c|c|c|c|c|c|}
\hline & \multicolumn{6}{|c|}{ Vitamer $(n M)^{*}$} \\
\hline & $\begin{array}{c}\text { PLP } \\
(57 \pm 26)\end{array}$ & $\begin{array}{c}\text { PL } \\
(23 \pm 10)\end{array}$ & $\begin{array}{c}\text { PN } \\
(19 \pm 33)\end{array}$ & $\begin{array}{c}\text { PM } \\
(2 \pm 2)\end{array}$ & $\begin{array}{l}\text { PMP } \\
(8 \pm 8)\end{array}$ & $\begin{array}{c}\text { 4-PA } \\
(49 \pm 19)\end{array}$ \\
\hline \multicolumn{7}{|l|}{ Patients } \\
\hline I & 5,800 & ND & ND & ND & ND & ND \\
\hline $\mathrm{II}^{\ddagger}$ & 14,600 & 837 & ND & ND & ND & 174 \\
\hline III $a^{\S}$ & 6,100 & ND & 197 & ND & ND & 61 \\
\hline$b^{\S}$ & 57,500 & 703 & 1,804 & ND & 45 & 312 \\
\hline$c^{\S}$ & 98,500 & 284 & 97 & 41 & 35 & 71 \\
\hline \multicolumn{7}{|l|}{ Controls } \\
\hline A & 275 & 255 & ND & ND & ND & 154 \\
\hline B & 180 & 361 & ND & ND & ND & 567 \\
\hline
\end{tabular}

ND, Not detected at the dilution tested.

* Normal values $(x \pm S D)$, given in parentheses, are from 38 adult control subjects (16).

‡ While receiving $0.6 \mathrm{mg}$ PN hydrochloride daily in parenteral feedings.

$\S$ a, Before PN therapy. b, After receiving $50 \mathrm{mg}$ PN i.v. once daily for 4 d. c, After PN had been increased to $75 \mathrm{mg}$ i.v. once daily for $18 \mathrm{~d}$. 
Table II. ALP Activity in Perinatal Hypophosphatasia*‡

\begin{tabular}{|c|c|c|c|c|c|c|c|}
\hline & Serum & Vertebra & Liver & Kidney & $\begin{array}{l}\text { Psoas } \\
\text { muscle }\end{array}$ & Brain & $\begin{array}{l}\text { Small } \\
\text { bowel }\end{array}$ \\
\hline \multicolumn{8}{|c|}{ Patient } \\
\hline I & 6 & ND & ND & 17 & 1 & ND & 2,085 \\
\hline II & 16 & ND & ND & 1 & ND & ND & 1,038 \\
\hline III & $<5$ & - & - & - & - & - & - \\
\hline \multicolumn{8}{|c|}{ Controls } \\
\hline I & - & 124 & 26 & 25 & 6 & - & 232 \\
\hline II & - & 100 & 82 & 25 & 10 & 8 & 200 \\
\hline III & - & 60 & 5 & 25 & 8 & - & 245 \\
\hline A & 135 & - & - & - & - & - & - \\
\hline B & 109 & - & - & - & - & - & - \\
\hline
\end{tabular}

* In tissues, milliinternational units per milligram protein.

* ND, Not detected.

Normal range, 75 to 250 IU/liter.

Whether expressed per tissue protein, DNA content, or wet weight, PLP levels were essentially unremarkable in all of the patient organs sampled except the small intestine, where increased ALP activity was associated with somewhat lower PLP levels (Table III). The vertebra of patient II (primarily unmineralized osteoid), who had received PN supplementation, had about a sevenfold greater content of PLP than vertebrae from controls.

Tissue levels of PL were unremarkable in patients except for the vertebrae, where levels were lower than in two of the three controls (Table IV), and in the muscle of patient II, who was treated with PN, where the PL level was increased (Table IV). The total amount of B6 was essentially unremarkable in the patient tissues (Table V).

\section{Discussion}

Hypophosphatasia in our patients was documented by a consistent clinical presentation and physical findings, hypophosphatasemia, radiographic and histopathologic changes of rickets, markedly increased levels of plasma PLP, and profound deficiency of ALP activity in tissues other than intestine $(5,7)$.

Abundant ALP activity in the small intestine of the patients was expected in this genetic disorder, wherein TNSALP activity, but not intestinal or placental ALP isoenzyme activity, is deficient (5). Indeed, the patients appeared to have more ALP activity in their small bowel than did the controls. This observation has been described in infantile hypophosphatasia (17), and in one family with the more mild childhood/adult form (18). It perhaps reflects a regulatory defect of the ALP family of genes (13), or a compensatory increase in intestinal ALP activity $(19,20)$.

Although the genetic defect(s) is unknown, our discovery that plasma PLP levels are markedly elevated in hypophosphatasia revealed that TNSALP acts in B6 metabolism (7). As summarized below, appreciation of both the clinical manifestations of this disorder and the metabolic processing of B6 (8) suggests that TNSALP acts as an ectoenzyme to regulate extracellular but not intracellular levels of PLP.

PL, PN, pyridoxamine (PM) - three dietary sources of B6 -are each normally converted in the liver to PLP. Organ ablation studies in dogs indicate that mammalian liver is the principal source of circulating PLP, where $\sim 95 \%$ is protein bound (8). Before it can act peripherally, circulating PLP is dephosphorylated to PL, the B6 vitamer that can traverse plasma membranes. Within the cell, PL is converted to the B6 cofactor forms PLP and pyridoxamine-5'-phosphate (PMP) (8, 21). Intracellular levels of PLP are regulated by multiple factors including protein binding of PLP, product inhibition of PLP/PMP oxidase by PLP, and phosphatase activity. Ultimately, intracellular B6 is degraded primarily to 4-PA, which is excreted in the urine (8).

Increased plasma levels of both free and protein-bound PLP in hypophosphatasia indicate that TNSALP dephosphorylates PLP (7). However, the clinical findings in hypophosphatasia suggest that B6 levels are normal within tissues. Subjects with the various clinical forms of hypophosphatasia generally do not have symptoms of B6 deficiency or excess $(5,7)$. Dermatitis, stomatitis, peripheral neuritis, depression, or ane-

Table III. PLP Levels in Hypophosphatasia Tissues*

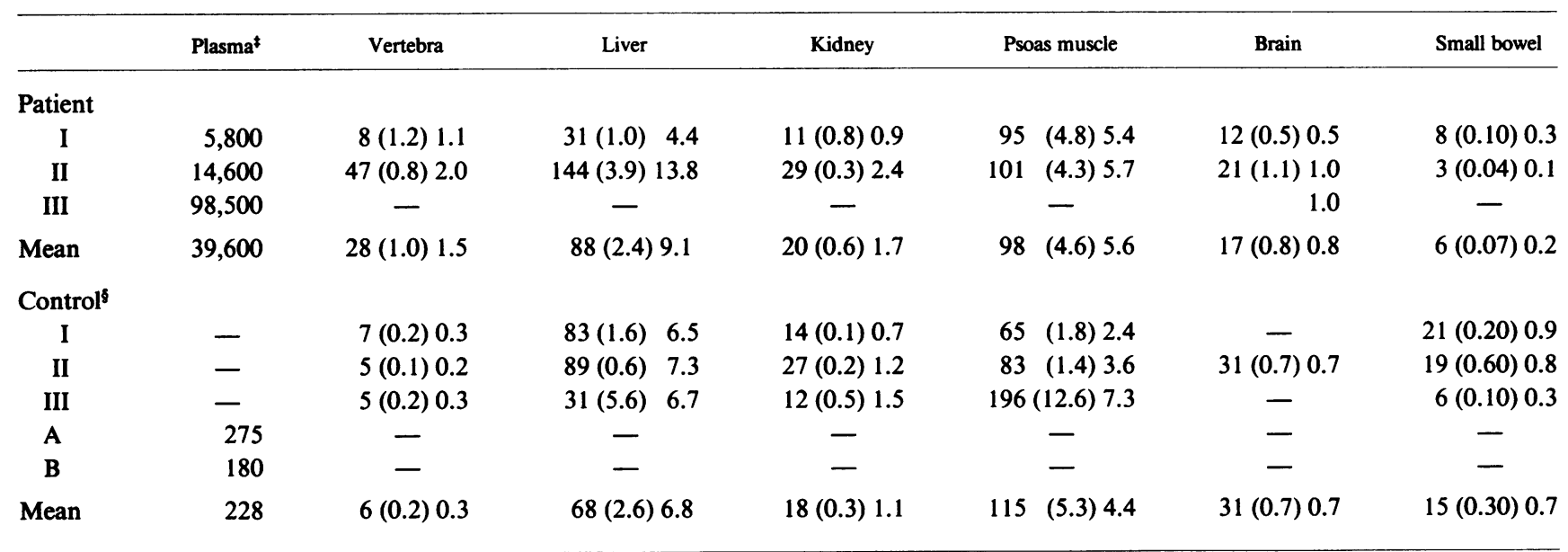

* Nanomoles per gram protein (nanomoles per milligram DNA) nanomoles per gram wet weight. $\quad{ }^{\ddagger}$ Normal adult range, $<109 \mathrm{nM}$. ${ }^{\S} \mathrm{Con}-$ trol subjects A and B are different from those from whom autopsy tissue was obtained (I-III). 
Table IV. PL Levels in Hypophosphatasia Tissues*

\begin{tabular}{|c|c|c|c|c|c|c|c|}
\hline & Plasma $^{\ddagger}$ & Vertebra & Liver & Kidney & Psoas muscle & Brain & Small bowel \\
\hline \multicolumn{8}{|c|}{ Patient } \\
\hline I & - & $29(4.6) 4.3$ & 43 (1.3) 6.0 & $70(5.6) \quad 6.2$ & $45(2.2) \quad 2.6$ & $42(1.7) 1.8$ & $160(1.9) 5.8$ \\
\hline III & 284 & - & - & - & - & - & - \\
\hline Mean & 561 & $26(2.5) 2.6$ & 50 (1.4) 5.8 & $120(3.8) 10.0$ & $117(5.9) \quad 7.6$ & 34 (1.5) 1.5 & $145(2.3) 5.8$ \\
\hline II & - & $95(1.7) 3.6$ & $64(0.5) 5.3$ & $187(1.0) \quad 8.3$ & $82(1.4) \quad 3.6$ & $45(1.0) 1.0$ & $147(4.5) 6.2$ \\
\hline III & - & $25(0.9) 1.7$ & $8(1.4) 1.7$ & $31(1.2) 3.7$ & $27(1.7) \quad 1.0$ & - & 70 (1.4) 3.2 \\
\hline A & 255 & - & - & - & - & - & - \\
\hline B & 361 & - & - & - & - & - & - \\
\hline Mean & 308 & $98(2.4) 4.3$ & $40(1.0) 3.6$ & $126(1.3) \quad 6.8$ & $55(1.6) \quad 2.2$ & $45(1.0) 1.0$ & $108(2.3) 4.7$ \\
\hline
\end{tabular}

* Nanomoles per gram protein (nanomoles per milligram DNA) nanomoles per gram wet weight. ${ }^{\ddagger}$ Normal adult range, $<43 \mathrm{nM} .{ }^{\S}$ Control subjects $\mathrm{A}$ and $\mathrm{B}$ are different from those from whom autopsy tissue was obtained (I-III).

mia-clinical hallmarks of B6 deficiency (22)-are not present, although seizures (e.g., patient III) and nephrocalcinosis have been reported in some affected infants (5). B6 deficiency has been associated with epilepsy and renal stone disease from altered oxalate metabolism (22); however, nephrocalcinosis is readily explained by the hypercalciuria and hypercalcemia that occur frequently in this severe form of hypophosphatasia (5). Similarly, epilepsy is not unexpected where cranial deformity and periodic apnea may occur. Furthermore, recent evidence indicates that high endogenous levels of phosphoethanolamine-another apparent natural substrate for TNSALP - may be epileptogenic (23). Osteoporosis and poor fracture callus formation, not rickets/osteomalacia, occurs in B6-deficient rats (24). Conversely, B6 excess causes peripheral neuropathy (25), but this problem is also not a feature of hypophosphatasia.

Since plasma membranes are impermeable to PLP, a defect that increases intracellular levels of PLP by decreased degradation or increased biosynthesis would not be expected to cause the elevated extracellular PLP levels observed in hypophosphatasia. Herein, we found direct evidence that tissue levels of B6 are normal in hypophosphatasia. Despite elevated plasma PLP concentrations (50-900-fold greater than the upper limit of normal for adults), patient tissue levels of PLP, PL, and total B6 vitamers were essentially unremarkable. Some variability in tissue B6 levels was observed. Patient II had received PN parenterally; this may explain why PLP levels in some of his tissues were greater than in patient $I$ or in the three controls. PLP levels in the patient vertebrae were severalfold increased compared with controls. Patient rachitic bone consisted of nearly $100 \%$ (rather than $2-8 \%$ ) protein matrix (osteoid) instead of hard tissue (13). Accordingly, the PN supplementation of patient II (with the especially high attendant PLP levels) together with the osteoidosis of both patients may, in part, explain this observation. Our finding that PLP, but not PL, levels seemed somewhat lower in the small bowel of the patients may be related to the increased ALP activity observed in this tissue. Of interest, a cytosolic form of intestinal ALP has been identified in fetal small intestine (20).

Some postmortem change in the tissue levels of the various forms of B6 likely occurred in our study, but we believe the magnitude of the changes should not alter the interpretation of our findings. Andon and Reynolds recently reported that PLP levels in the muscle of pigs kept at $25^{\circ} \mathrm{C}$ after killing decreased by $35 \%$ within $6 \mathrm{~h}$ and $45 \%$ at $12 \mathrm{~h}(26)$. They did not measure other forms of B6. In our study, tissues were obtained 12-24 h

Table V. Total B6 in Hypophosphatasia Tissues*

\begin{tabular}{|c|c|c|c|c|c|c|c|}
\hline & Vertebra & & Liver & Kidney & Psoas muscle & Brain & Small bowel \\
\hline \multicolumn{8}{|l|}{ Patient } \\
\hline I & $38(6.2) 6$ & 93 & (3.0) 13 & $118(9.5) 11$ & $166 \quad(8.3) 10$ & $63(2.5) 3$ & $207(2.5) \quad 8$ \\
\hline Mean & $61(3.8) 5$ & 189 & (5.3) 20 & $188(6.0) 16$ & $265(12.0) 15$ & $64(2.9) 3$ & $207(3.3) \quad 9$ \\
\hline \multicolumn{8}{|c|}{ Control } \\
\hline III & $40(1.5) 3$ & 63 & (11.3) 14 & $71(2.8) 9$ & $290(18.6) 11$ & - & $142(2.8) 7$ \\
\hline Mean & $100(3.0) 5$ & 163 & $(5.5) 16$ & $189(2.3) 11$ & $214 \quad(8.8) \quad 8$ & $104(2.2) 2$ & $196(4.0) \quad 9$ \\
\hline
\end{tabular}

* Nanomoles per gram protein (nanomoles per milligram DNA) nanomoles per gram wet weight. 
after demise from corpses that had been promptly refrigerated. The amount of PLP and total B6 observed in liver from our young subjects was $25-50 \%$ of the levels reported by Merrill et al. in normal adults (27). Accordingly, the similarity between the B6 levels observed in our patient and control tissues indicates that their premortem B6 levels were probably not significantly different. Certainly, any differences in tissue B6 concentrations are much smaller than the marked differences in plasma PLP levels. The limited number of patients and wide range of tissue B6 vitamer levels in our study preclude specific conclusions about the relative B6 vitamer concentrations in individual tissues.

A variety of evidence indicates that, in the circulation, soluble ALP and the cellular elements contribute little to the hydrolysis of PLP $(21,28)$. TNSALP on cell surfaces would appear, therefore, to dephosphorylate PLP to PL extracellularly. In hypophosphatasia, PL levels in the circulation could be low and result in clinical and biochemical evidence of B6 deficiency. Of interest, in the patients reported herein, i.e., those most severely affected by hypophosphatasia (perinatal form), PL levels were undetectable $(<10 \mathrm{nM})$ before PN supplementation, but were corrected with PN treatment. In the more mild forms of hypophosphatasia, we found normal or somewhat increased plasma PL levels (7). The current observations are consistent with reduced dephosphorylation of PLP to PL with extreme TNSALP deficiency. Normal or increased PL levels in the more mild forms of hypophosphatasia may reflect, in part, the presence of some residual TNSALP activity.

After our report of increased plasma PLP levels in hypophosphatasia (7), Lumeng reviewed that paper and the in vitro evidence for a possible intracellular role of ALP on hepatic PLP metabolism, and called for additional studies to support our hypothesis (12). We note that Merrill and co-workers concluded that ALP activity may be too low at physiologic $\mathrm{pH}$ to have any important regulatory role in B6 metabolism (27). However, in in vitro studies where ALP activity is traditionally assayed with a variety of artificial substrates (e.g., p-nitrophenylphosphate) at nonphysiologic (alkaline) pH, ALP activity is generally diminished at more physiologic pHs (1). Indeed, Lumeng and $\mathrm{Li}$ found that with low substrate concentration, PLP phosphatase activity in liver plasma membranes is greater at pH 7.4 than at pH 9 (9). We have also recently noted that natural substrates, including PLP, are hydrolyzed effectively at physiologic concentration and $\mathrm{pH}$ by TNSALP in cultivated osteosarcoma cells (29). Furthermore, we have demonstrated that PLP levels are normal in homogenates of cultivated ALPdeficient fibroblasts from subjects with infantile hypophosphatasia (30). Previously, we reported that urinary levels of 4-PA were normal in all four subjects we examined with the childhood form of hypophosphatasia (7).

Although the molecular defect(s) in hypophosphatasia remains to be elucidated, the observations made in these TNSALP-deficient patients indicate a predominantly ectoenzyme role for TNSALP. This conclusion is in keeping with the well-established glycoprotein nature of the TNSALP isoenzyme family, and recent evidence that TNSALP may be covalently linked to the polar head group of phosphatidylinositol $(31,32)$ and oriented to the extracellular surface of the plasma membrane (29). Since the factors that regulate intracellular levels of PLP are complex, we would not have expected to find increments in hypophosphatasia tissue PLP levels of the mag- nitude observed in plasma if, indeed, TNSALP functions intracellularly. However, perinatal hypophosphatasia tissue levels of B6 do not appear to be at all abnormal. This is evidence that TNSALP acts as an ectoenzyme and that phosphatases other than TNSALP regulate intracellular levels of the phosphorylated cofactor forms of B6. Indeed, other intracellular PLP phosphatases have been reported, but their physiologic role requires clarification $(33,34)$.

In most bone and liver diseases (wherein circulating and tissue levels of TNSALP are increased), plasma PLP levels seem to be lowered (35), yet it is unclear if intracellular PLP concentrations are altered (36). Our findings indicate that circulating PLP levels may not reflect B6 nutrition when tissue ALP activity is abnormal. As recommended by Lumeng (12), we are currently pursuing functional studies of intracellular B6 status (L-tryptophan challenge) in hypophosphatasia.

\section{Acknowledgments}

We are grateful to Ms. Denise Wise and Mrs. Carolyn C. Lane for technical assistance, and to Mrs. Annette Skidmore for secretarial help.

This work was supported in part by a grant-in-aid from The Shriners Hospitals for Crippled Children; by grant 85-CRCR-1-1554 from the U. S. Department of Agriculture Competitive Grants Program; by University of Colorado School of Medicine Special Project of Regional and National Significance grant MCT 00252 from The Bureau of Community Health Services; and by grant RR-00069 from the General Clinical Research Center Branch, Division of Research Facilities and Resources, National Institutes of Health.

\section{References}

1. McComb, R. B., G. N. Bowers, Jr., and S. Posen. 1979. Alkaline Phosphatase. Plenum Publishing Corp., New York.

2. Whyte, M. P. 1983. Alkaline phosphatase and the measurement of bone formation. In Clinical Disorders of Bone and Mineral Metabolism. B. Frame and J. T. Potts, Jr., editors. Excerpta Medica, Amsterdam. 120-124.

3. Fallon, M. D., M. P. Whyte, and S. L. Teitelbaum. 1980. Stereospecific inhibition of alkaline phosphatase by L-tetramisole prevents in vitro cartilage calcification. Lab. Invest. 43:489-494.

4. Rathbun, J. C. 1948. Hypophosphatasia, a new developmental anomaly. Am. J. Dis. Child. 75:822-831.

5. Rasmussen, H. 1983. Hypophosphatasia. In The Metabolic Basis of Inherited Disease. 5th ed. J. B. Stanbury, J. Wyngaarden, D. S. Fredrickson, J. L. Goldstein, and M. S. Brown, editors, McGraw-Hill, Inc., New York. 1497-1507.

6. Wuthier, R. E., and T. C. Register. 1985. Role of alkaline phosphatase, a polyfunctional enzyme, in mineralizing tissue. In The Chemistry and Biology of Mineralized Tissues. W. T. Butler, editor. EBSCO Media, Birmingham, AL. 113-124.

7. Whyte, M. P., J. D. Mahuren, L. A. Vrabel, and S. P. Coburn: 1985. Markedly increased circulating pyridoxal-5'-phosphate levels in hypophosphatasia. Alkaline phosphatase acts in vitamin B6 metabolism. J. Clin. Invest. 76:752-756.

8. Shideler, C. C. 1983. Vitamin B6: an overview. Am. J. Med. Technol. 49:17-21.

9. Lumeng, L., and T.-K. Li. 1975. Characterization of the pyridoxal-5'-phosphate and pyridoxamine 5'-phosphate hydrolase activity in rat liver: identity with alkaline phosphatase. J. Biol. Chem. 250:8126-8131.

10. Wilson, P. D., G. P. Smith, and T. J. Peters. 1983. Pyridoxal 5'-phosphate: a possible physiological substrate for alkaline phosphatase in human neutrophils. Histochem. J. 15:257-264.

11. Whyte, M. P., and L. A. Vrabel. 1987. Infantile hypophosphatasia fibroblasts proliferate normally in culture: evidence against a role 
for alkaline phosphatase (tissue nonspecific isoenzyme) in the regulation of cell growth and differentiation. Calcif. Tissue Int. 40:1-7.

12. Lumeng, L. 1986. Pyridoxal-5'-phosphate and alkaline phosphatase. Hepatology. 6:330-331.

13. Whyte, M. P., H. L. Magill, M. D. Fallon, and H. G. Herrod. 1986. Infantile hypophosphatasia: normalization of circulating bone alkaline phosphatase activity followed by skeletal remineralization. Evidence for an intact structural gene for tissue nonspecific alkaline phosphatase. J. Pediatr. 108:82-88.

14. McComb, R. B., and G. N. Bowers, Jr. 1979. Procedures. In Alkaline Phosphatase. R. B. McComb, G. N. Bowers, Jr., and S. Posen, editors. Plenum Publishing Corp., New York. 903-907.

15. LaBarca, C., and K. Paigen. 1980. A simple, rapid, and sensitive DNA assay procedure. Anal. Biochem. 102:344-352.

16. Coburn, S. P., and J. D. Mahuren. 1983. A versatile cation-exchange procedure for measuring the seven major forms of vitamin B6 in biological samples. Anal. Biochem. 129:310-317.

17. Vanneuville, F. J., and J. G. Leroy. 1981. Enzymatic diagnosis of congenital lethal hypophosphatasia in tissues, plasma and diploid skin fibroblasts. J. Inherited Metab. Dis. 4:129-130.

18. Danovitch, S. H., P. N. Baer, and L. Laster. 1968. Intestinal alkaline phosphatase activity in familial hypophosphatasia. $N$. Engl. $J$. Med. 278:1253-1260.

19. Mueller, H. D., R. A. Stinson, F. Mohyuddin, and J. K. Milne. 1983. Isoenzymes of alkaline phosphatase in infantile hypophosphatasia. J. Lab. Clin. Med. 102:24-30.

20. Mueller, H. D., H. Leung, and R. A. Stinson. 1985. Different genes code for alkaline phosphatase from human fetal and adult intestine. Biochem. Biophys. Res. Commun. 126:427-433.

21. Lumeng, L., S. Schenker, T.-K. Li, R. E. Brashear, and M. C. Compton. 1984. Clearance and metabolism of plasma pyridoxal, 5'phosphate in the dog. J. Lab. Clin. Med. 103:59-69.

22. Rivlin, R. S. 1985. Disorders of vitamin metabolism: deficiencies, metabolic abnormalities, and excesses. In Cecil Textbook of Medicine. 17th ed. J. B. Wyngaarden and L. H. Smith, Jr., editors. W. B. Saunders Co., Philadelphia. 1197-1209.

23. Takahashi, T., A. Iwatanti, S. Mizuno, Y. Morishita, H. Nishio, S. Kodama, and T. Matsuo. 1984. The relationship between phosphoethanolamine level in serum and intractable seizure on hypophosphatasia infantile form. In Endocrine Control of Bone and Calcium Metabolism. Vol. 8-B. D. V. Cohn, T. Fujita, and J. T. Potts, Jr., editors. Excerpta Medica, Amsterdam. 93-94. (Abstr.)

24. Dodds, R. A., A. Catterall, L. Bitensky, and J. Chayen. 1986.
Abnormalities in fracture healing induced by vitamin B6-deficiency in rats. Bone. 7:489-495.

25. Schaumburg, H., J. Kaplan, A. Windebank, N. Vick, S. Rasmus, D. Pleasure, and M. J. Brown. 1983. Sensory neuropathy from pyridoxine abuse: a new megavitamin syndrome. $N$. Engl. $J$. Med. 309:445-448.

26. Andon, M. B., and R. D. Reynolds. 1987. Pyridoxal phosphate concentrations determined post-mortem as an indication of antemortem vitamin B6 status. Proc. Soc. Exp. Biol. Med. 184:285-290.

27. Merrill, A. H., J. M. Henderson, E. Wang, B. W. McDonald, and W. J. Millikan. 1984. Metabolism in vitamin B6 by human liver. J. Nutr. 114:1664-1674.

28. Whyte, M. P., W. H. McAlister, L. S. Patton, L. H. Magill, M. D. Fallon, W. B. Lorentz, and H. G. Herrod. 1984. Enzyme replacement therapy for infantile hypophosphatasia attempted by intravenous infusions of alkaline phosphatase-rich Paget plasma: results in three additional patients. J. Pediatr. 105:926-933.

29. Fedde, K. N., C. C. Lane, and M. P. Whyte. 1987. Alkaline phosphatase is an ectoenzyme for natural substrates at physiologic $\mathrm{pH}$ in osteoblast-like cells. J. Bone Min. Res. 2(Suppl. 1):A-240. (Abstr.)

30. Whyte, M. P., J. D. Mahuren, M. J. Scott, and S. P. Coburn. 1986. Hypophosphatasia: pyridoxal-5'-phosphate levels are markedly increased in hypophosphatasemic plasma but normal in alkaline phosphatase-deficient fibroblasts. Evidence for an ectoenzyme role for alkaline phosphatase in vitamin B6 metabolism. J. Bone Min. Res. 1:92. (Abstr.)

31. Low, M. G., and D. B. Zilversmit. 1980. Role of phosphatidylinositol in attachment of alkaline phosphatase to membranes. Biochemistry. 19:3913-3918.

32. Low, M. G., and A. R. Saltiel. 1988. Structural and functional roles of glycosyl-phosphatidylinositol in membranes. Science (Wash. DC). 239:268-275.

33. Kyaw, A. 1980. A nuclear phosphatase that specifically hydrolyzes pyridoxal phosphate in mouse liver. Biochem. Med. 24:27-32.

34. Coleman, R. A., B. H. Schofield, and D. F. McDonald. 1980. Selective localization of a golgi apparatus acid phosphatase isoenzyme in bone using pyridoxal-5'-phosphate. J. Histochem. Cytochem. 28:115-123.

35. Anderson, B. B., H. O'Brien, G. E. Griffin, and D. L. Mollin. 1980. Hydrolysis of pyridoxal 5 '-phosphate in plasma in conditions with raised alkaline phosphatase. Gut. 21:192-194.

36. Potera, C., D. P. Rose, and R. R. Brown. 1977. Vitamin B6 deficiency in cancer patients. Am. J. Clin. Nutr. 30:1677-1679. 